ХОДИНОВА Ольга Сергеевна - аспирант Дипломатической академии Министерства иностранных дел Российской Федерации (119021, Россия, г. Москва, ул. Остоженка 53/2, стр. 1; olga. khodinova@gmail.com)

\title{
ЕВРОПЕЙСКИЙ ИНТЕРКУЛЬТУРАЛИЗМ НА ПРАКТИКЕ: СОВРЕМЕННАЯ ГОРОДСКАЯ ПОЛИТИКА ФРАНЦИИ
}

Аннотация. Статья посвящена анализу новейших тенденций в управлении культурным разнообразием в Европейском союзе. Автор показывает, что новая концепция интеркультурализма предлагает европейским политикам для решения национальных миграционных и социальных проблем уделять, прежде всего, пристальное внимание работе на муниципальном уровне. Практическое выражение этих рекомендаций - запущенная еще в 2008 г. программа «Межкультурные города».

Ключевые слова: Франция, Европейский союз, миграционная политика, межкультурный диалог, интеркультурализм, мигранты, городская политика

$\mathrm{B}$ поисках ответа на постмультикультуралистские вызовы европейское политическое сообщество пришло к концепции межкультурного диалога как необходимого средства «для предотвращения конфликтов и маргинализации граждан на основе их культурной самобытности» ${ }^{1}$. Вектор этой политики был задан еще в 2008 г., в Белой книге Совета Европы по межкультурному диалогу «Жить вместе в равном достоинстве» 2 . В настоящее время межкультурный диалог назван приоритетным стратегическим направлением культурной политики EC: «в отличие от мультикультурализма, где основное внимание уделяется сохранению отдельных культур, межкультурный диалог стремится установить связи и точки соприкосновения между различными культурами, сообществами и людьми, способствуя взаимопониманию и взаимодействию» ${ }^{3}$. В основе концепции - идея уникальности каждой культуры вне зависимости от расы, религии, языка, происхождения ее носителя, идея диалога, а также продуктивного взаимодействия и взаимопроникновения культур. В рамках интеркультурализма отношения строятся по принципу «государство - гражданин», а не «государство - группа», как это было задано концепцией мультикультурализма.

На веб-сайте Европейской комиссии обозначено, что за 2017-2018 гг. в рамках программы Creative Europe были профинансированы 12 проектов по интеграции беженцев ${ }^{4}$. Программа рассчитана на 7 лет, с 2014 по 2020 г., и включает в себя образовательные проекты (Erasmus + ), проекты в сфере здравоохранения, создание высокотехнологичных рабочих мест, улучшение доступа малого бизнеса на рынки и др. Бюджет составляет 1,4 млрд евро. Практическое измерение этих инициатив представляет собой совместная программа Совета Европы и Еврокомиссии «Межкультурные города», запущенная еще в 2008 г. Изначально в нее вошли 11 городов, включая российский Ижевск. Сегодня программа

\footnotetext{
${ }^{1}$ Intercultural dialogue. - Official web-site of the European Commission. URL: https://ec.europa.eu/culture/ policy/strategic-framework/intercultural-dialogue_en (accessed 20.02.2019).

2 Paper on Intercultural Dialogue «Living Together As Equals in Dignity». URL: http://www.coe.int/t/dg4/ intercultural/source/white\%20paper_final_revised_en.pdf (accessed 05.12.2018).

3 Intercultural dialogue. - Official web-site of the European Commission. URL: https://ec.europa.eu/culture/ policy/strategic-framework/intercultural-dialogue_en (accessed 20.02.2019).

4 Подробнее см.: EU cultural policies and programmes. URL: https://www.kreativwirtschaft.at/wp-content/uploads/2016/01/BarbaraStacher_ExpertentreffenKreativwirtschaft_Sept.151.pdf (accessed 20.02.2019).
} 
включает 135 городов по всему миру. На сайте Совета Европы с периодичностью в несколько месяцев публикуются различные отчеты, обновляется индекс городов. 28 февраля 2019 г. появилось пособие в форме интерактивного мануала для руководителей местного уровня по привлечению иммигрантов к урегулированию чрезвычайных ситуаций ${ }^{1}$. Инструкции были разработаны при участии Международной организации по миграции. А неделей ранее в Ижевске побывали эксперты проекта, провели ревизию городских социальных и культурных ресурсов $^{2}$. Еврокомиссия также создала отдельный интернет-портал, посвященный этой проблеме, - Европейский веб-сайт по интеграции ${ }^{3}$, где регулярно публикуются новости о разнообразных инициативах и реализации различных межкультурных проектов в Испании, Италии, Португалии, Франции и других странах, всего более 400 примеров передовой практики, касающихся межкультурного диалога, управления культурным разнообразием и вовлечения иммигрантов в социальную среду. Есть среди них и новости за 2019 г.

Таким образом, определенная практическая работа европейскими институтами ведется, однако каких-либо общеевропейских «дорожных карт» по культуре на текущий и будущие годы ни на одном из интернет-ресурсов не обнаружено. В разделе «дальнейшие шаги» лишь указано, что между национальными правительствами продолжается политическое сотрудничество с акцентом на социальную интеграцию и что над темой «Содействие вкладу культуры в социальную интеграцию» в 2017-2018 гг. работала группа экспертов-добровольцев ${ }^{4}$

Между тем очевидно, что для Европейского союза, который так и не выработал единую стратегию приема мигрантов, проблема интеграции носителей неевропейского культурного кода и управления культурным разнообразием стоит крайне остро. Можно с уверенностью прогнозировать, что вопрос миграции вновь станет одним из ключевых в электоральной кампании перед выборами в Европейский парламент, которые пройдут в мае 2019 г. Уже сейчас эксперты предрекают создание крупного интернационального правого блока, состоящего из политических движений националистического толка из Австрии, Италии, Нидерландов и Франции 5 .

В научных и экспертных кругах вокруг концепции интеркультурализма и самого термина в настоящее время идут жаркие споры, звучат различные мнения (подробнее мы их рассматривали в предыдущем номере журнала [Ходинова 2019: 172]), например, такие: «всплеск миграционной активности провоцирует титульные культуры к осмыслению национальных паттернов и собственной идентичности. В круг актуальных вопросов входят вопросы о том, какие сферы жизни человека могут контролироваться государством, а какие должны остаться прерогативой личности и группы» [Ляпина 2014]. Защитники интеркультурализма говорят о необходимости смещения ракурса европейских дебатов о взаимосвязи единства нации и культурного разнообразия в сторону социальной политики, которая не отделяла бы иммигрантов от граждан: «в новом контексте суперразнообразия... происхождение и национальность не обязательно являются ключевыми факторами политики разнообразия, в игру всту-

\footnotetext{
${ }^{1}$ Including migrants in emergency management: a course for local-level practitioners. URL: https://www. coe.int/en/web/interculturalcities/-/including-migrants-in-emergency-management-a-course-for-local-level-practitioners (accessed 02.03.2019).

2 В Ижевске побывали эксперты проекта Совета Европы «Межкультурные города». Доступ: http:// www.izvestiaur.ru/news/view/16805001.html (проверено 25.02.2019).

3 European Web Site on Integration. URL: https://ec.europa.eu/migrant-integration/ (accessed 20.02.2019).

${ }^{4}$ Intercultural dialogue. - Official web-site of the European Commission. URL: https://ec.europa.eu/culture/ policy/strategic-framework/intercultural-dialogue_en (accessed 20.02.2019).

5 Выборы в Европарламент-2019. У кого больше шансов? Доступ: https://www.dw.com/ru/выборы-вевропарламент-2019-у-кого-больше-шансов/а-45500061 (проверено 20.02.2019).
} 
пают такие факторы, как социальный класс, пол, возраст, текущая правовая ситуация, условия работы» [Zapata-Barrero 2017]. Согласно данным из последнего доклада Национального института статистики и экономических исследований (INSEE), 4 из 10 иммигрантов при приеме на первую работу во Франции плохо или вообще не говорят по-французски ${ }^{1}$. Как отмечает французский социолог Мишель Вевьёрка, «культурное различие никогда, ни при каких условиях нельзя отделить от набора социальных проблем, от несправедливости, неравенства, упадка» [Вевьёрка 2005: 16]. Пристальное внимание к социальным проблемам на локальном уровне, уровне муниципалитета - то, что отличает интеркультурализм от других интеграционных концепций.

Франция на протяжении почти века проводила миграционную политику ассимиляционистского толка, однако мигранты, становясь гражданами страны, не спешили отказываться от своих культурных кодов и корней. Сегодня интеркультурализм, на наш взгляд, может стать решением многолетней французской проблемы поиска адекватной современным реалиям модели интеграции иммигрантов, а также успешного соседства, сожительства с теми носителями неевропейского культурного кода, кто является французом уже даже во втором и третьем поколении, однако так и не ассимилировался. Основы для этого были заложены еще 40 лет назад.

Термин «городская политика», или «политика города» (la politique de la ville) возник во французском политическом дискурсе в 1980-х гг. и использовался для описания всех действий, предпринимаемых государством для обновления районов, которые в этом больше всего нуждались: как правило, это были пригороды, построенные в 1960-7190-х гг. для иностранных рабочих, поднимавших в то время экономику республики. Комплекс мер включал и экономическое развитие, и улучшение жилищных условий, и безопасность, и доступ к образованию, культуре, общественным объектам и т.д. В 1990 г. было создано специальное ведомство, которое сегодня носит название Министерства территориальной сплоченности и отношений между территориальными коллективами (Ministère de la Cohésion des territoires et des Relations avec les collectivités territoriales). Его главная функция - надзор за действиями государства, направленными на «улучшение условий жизни жителей» в наиболее неблагополучных районах ${ }^{2}$. В то же время «политика города» требует партнерства между государством и местными властями, а также сотрудничества между различными ведомствами: так, например, МВД контролирует так называемые приоритетные зоны безопасности $(Z S P)$, Министерство национального образования - «зоны приоритетного образования» (ZEP). Как справедливо отмечает сотрудница Института исследований арабского и мусульманского мира (IREMAM) Франсуаза Лорсери, обучение играет решающую роль в определении жизненной траектории. Если человек преуспевает в школе, он, вероятно, покинет район и изменит свою социальную жизнь. В противном случае он останется «в заложниках у социальной среды, часто безработный, иногда вовлеченный в девиантную деятельность» [Lorcerie 2012].

Пристальное внимание вопросу соседства французские власти начали уделять еще до наплыва мигрантов в Европейский союз. В 2014 г. вышел так называемый закон Лами - о городском планировании и сплоченности городов, который заложил основы Новой национальной программы обновления городов 2014-

${ }^{1}$ L'insertion des immigrés, de l'arrivée en France au premier emploi. - Insee Première. $\mathrm{N}^{\circ} 1717$. Novembre 2018. Доступ: https://ec.europa.eu/migrant-integration/librarydoc/linsertion-des-immigres-de-larrivee-enfrance-au-premier-emploi?lang=en (проверено 20.02.2019).

2 Politique de la ville. - Ministère de la Cohésion des territoires et des Relations avec les collectivités territoriales. Доступ: http://www.cohesion-territoires.gouv.fr/politique-de-la-ville (проверено 18.12.2018). 
$2024(N P N R U)^{1}$. Тогда же были определены и перечислены 1540 приоритетных городских районов (les quartiers prioritaires de la ville, $Q P V)$ - зон особой чувствительности, в которых проживали 5,5 млн чел². В 2016 г. Национальная обсерватория городской политики (ONPV) подсчитала, что 42,6\% населения этих кварталов живут в бедности, а уровень безработицы составляет $25,3 \%{ }^{3}$. Среди таких $Q P V-4$ района в агломерации Лиона, так называемой Лионской метрополии 4 . И это при том, что этот третий по численности город Франции с 2008 г. - «межкультурный город». Такие же гетто существуют в Париже, Страсбурге (они также включены в программу «межкультурных городов»), Марселе, Бордо и других крупных городах Франции. Недавно программа NPNRU была продлена до 2030 г.

Президент Э. Макрон активно взялся за городскую политику. По его поручению бывший министр городской политики Жан-Луи Борло в апреле 2018 г. выступил с докладом «Жить вместе, жить по-настоящему - для национального примирения». В нем проведен анализ обстановки в бедных районах (les quartiers): там больше молодежи и при этом в 2 раза меньше детей ходят в школу и в 3 раза меньше - в подготовительные классы; жители этих районов имеют более разнообразное культурное происхождение; там меньше социальных услуг, библиотек, центров занятости, спортивно-досуговых центров; хуже развита сеть общественного транспорта; 2/3 домов - социальное жилье, построенное еще в 1970-х гг; меньше специализированных врачей; в 2 раза больше людей чувствуют себя «неуверенно»; в 3 раза больше людей подвергаются дискриминации; уровень безработицы почти в 3 раза выше, чем в среднем по стране 5 . В итоге французские власти получают серьезную социальную силу, которая не поддается управлению: это необразованные, маргинализированные молодые люди в самом беспокойном возрасте, полные сил и амбиций.

В докладе бывшего министра Борло содержится призыв к национальной мобилизации и предлагаются 19 тематических программ, в т.ч. забота о раннем детстве, новая школа, новая армия, защита здоровья, борьба с дискриминацией и - что крайне важно - культурное образование, акцент на восприятии культуры «другого»: «знакомство с “другим” - это основа действительно инклюзивного и сплоченного общества, его цемент. <...> Необычность, разнообразие - это шанс для нашей страны и ее богатство. Не может быть образования и ставок на будущее без учета этой реальности, и мы должны начать с молодых людей. Если этого не сделать, череда разочарований и социальной напряженности будет продолжать расти, только усиливая социальные, культурные и территориальные различия» 6 .

Президент Макрон, однако, решил отказаться от «плана Борло», заявив, что «старые, как он сам», методы устарели и нужна серьезная реформа политики соседства. 22 мая 2018 г. он объявил о создании Президентского совета городов и о новой программе «коллективных действий»: «Это политика, которая заключается в том, чтобы повсюду, во всех местах Республики наши сограж-

\footnotetext{
${ }^{1}$ Nouveau Programme National de Renouvellement Urbain. Доступ: https://www.anru.fr/fre/Programmes/ Nouveau-Programme-National-de-Renouvellement-Urbain (проверено 23.12.2018).

2 Politique de la ville: quelles orientations après le rapport Borloo? Доступ: http://www.vie-publique.fr/actualite/dossier/qpv/politique-ville-quelles-orientations-apres-rapport-borloo.html (проверено 23.12.2018).

3 Ibid.

4 Quatre “quartiers ghettos” dans l'agglomération lyonnaise selon le JDD. Доступ: https://www.lyonmag. com/article/70332/quatre-8220-quartiers-ghettos-8221-dans-1-8217-agglomeration-lyonnaise-selon-le-jdd (проверено 23.12.2018).

5 Vivre ensemble, vivre en grand pour une réconciliation nationale. Доступ: http://www.cohesion-territoires. gouv.fr/IMG/pdf/sra4_complet.pdf (проверено 23.12.2018).

6 Ibid.
} 
дане обрели свое достоинство» ${ }^{1}$. Среди перечисленных мер следует отметить: дополнительный набор 1300 полицейских в 60 районах к 2020 г;; построение «общества всеобщей бдительности» для сведения к минимуму террористической угрозы от радикалов и экстремистов (сейчас в списках подозрительных лиц - 20000 чел.), а также наркотрафика; создание 30000 мест для стажировки молодых специалистов; тестирование в ближайшие 3 года 120 крупнейших французских компаний для борьбы с трудовой дискриминацией ${ }^{2}$.

Особое внимание в своей майской речи, которую уже называют программной, президент Франции уделил сотрудничеству с мэрами. В июле 2018 г. правительство подписало коммюнике с главами 86 городов о реализации политики сплочения в $Q P V$, в котором был зафиксирован полугодовой период с сентября 2018 г., за который главы муниципалитетов должны пересмотреть свои управленческие стратегии в пользу политики социального сплочения 3 . Однако в феврале 2019 г. этот срок истек, а множество глав городов так и не поняли, в каком направлении двигаться. Так, судя по сообщениям в СМИ, 4 февраля 2019 г. Макрона ждал холодный прием на встрече с 40 главами муниципалитетов в городе Эссоне, куда он приехал в рамках «национальных дебатов» по следам протестных акций «желтых жилетов», которые требуют снижения налогов и социальной справедливости 4 . Макрон не смог ответить ни на один вопрос о практической реализации своей идеи.

Одной из главных трудностей на пути реализации во Франции вышеописанных мер, как представляется, может стать забюрократизированность. Так, помимо Президентского совета городов, в правительстве Э. Филиппа существует вышеупомянутое Министерство территориальной сплоченности. Оно опирается на Генеральный комиссариат по вопросам равенства территорий $(C G E T)$, который координирует «политику города». CGET отвечает за консультирование правительства по вопросам разработки национальной «политики города» и социального развития муниципалитетов. Также $C G E T$ управляет секретариатом Национальной обсерватории городов, отвечающим за контроль работы «Политики города». Под надзором Министерства территориальной сплоченности также находятся Национальное агентство жилищного строительства и Национальное агентство по обновлению городов, функции которых в отдельных сферах пересекаются.

Проведенный анализ показывает, что инициативы французских властей вполне своевременны и укладываются в концепцию интеркультурализма, обозначенную Советом Европы и Европейской комиссией как руководство к действию национальных правительств на европейском пространстве. Вместе с тем концепт межкультурного диалога все еще достаточно размыт, оформлен нечетко. На фоне продолжающихся поисков Брюсселем единой стратегии приема и интеграции мигрантов отсутствие инструментария для управления культурным разнообразием особенно бросается в глаза. На наш взгляд, это свидетельствует об определенном кризисе в европейском управлении. Успешность реализации социальных преобразований зависит от политической воли властей предержащих: вместо обтекаемых формулировок о гражданском достоинстве

\footnotetext{
${ }^{1}$ Discours du Président de la République. La France, une chance pour chacun. Доступ: https://www.elysee. fr/emmanuel-macron/2018/05/23/la-france-une-chance-pour-chacun (проверено 20.02.2019).

2 Discours du Président de la République. La France, une chance pour chacun. Доступ: https://www.elysee. fr/emmanuel-macron/2018/05/23/la-france-une-chance-pour-chacun (проверено 20.02.2019).

3 Signature de Pacte de Dijon. Доступ: https://www.gouvernement.fr/partage/10408-signature-du-pactede-dijon (проверено 20.02.2019).

4 Banlieues et Macron, le Borloo de la discorde. - Liberation. Доступ: https://www.liberation.fr/ france/2019/02/04/banlieues-et-macron-le-borloo-de-la-discorde_1707436 (проверено 20.02.2019).
} 
необходимо разработать ясную стратегию, план конкретных мер и систему контрольных показателей, а также победить бюрократию. Это равно применимо и к европейским, и к французским институтам власти.

\title{
Список литературы
}

Вевьёрка М. 2005. Формирование различий. - Социс. Социологические исследования. № 8. С. 13-24.

Ляпина Л.А. 2014. Эволюция либеральной концепции мультикультурализма. - Социологический альманах. № 5. С. 253-259.

Ходинова О. 2019. Интеркультурализм как новая стратегия включения мигрантов в европейскую нацию (на примере Франции). - Власть. Т. 27 . № 1. C. $170-176$.

Lorcerie F. 2012. France: le rejet de l'interculturalisme - International Journal of Migration Studies. P. 278-301. Доступ: https://hal.archives-ouvertes.fr/hal-00797917/ document (проверено 21.03.2019).

Zapata-Barrero R. 2017. Interculturalism in the Post-multicultural Debate: a Defense. - Comparative Migration Studies. Vol. 5. No. 14. URL: https://comparativemigrationstudies.springeropen.com/articles/10.1186/s40878-017-0057-z/ (accessed 21.03.2019).

KHODINOVA Ol'ga Sergeevna, postgraduate student at the Diplomatic Academy of the Russian Foreign Ministry (bld. 1, 53/2 Ostozhenka St, Moscow, Russia, 119021; olga.khodinova@gmail.com)

\section{EUROPEAN INTERCULTURALISM IN PRACTICE: MODERN URBAN POLICY OF FRANCE}

\begin{abstract}
The article analyzes the most current trends in the management of cultural diversity in the European Union. The author shows that the new concept of interculturalism is presented as a key strategic element to the modern European societies. The European Commission created an online platform called «European Web Site on Integration" where the good examples of intercultural projects are being published. In 2008, the Council of Europe and the European Commission presented the project «Intercultural cities" as a new approach to overcome cultural and religious differences between European citizens and the newcomers. It offers European politicians to address national migration and social problems by paying close attention first of all to work at the municipal level. Now 135 cities all over the world are in this program, three of which are French ones - they are Paris, Strasbourg and Lyon. The article observes the latest legislative and conceptual initiatives of the French authorities as an attempt to solve the problem of the coexistence of indigenous citizens with the carriers of non-European cultural code. However, the European Union has so far only outlined a new strategy, for the successful implementation of which it has yet to develop a comprehensive program of intercultural interaction. Therefore, now there is still no joint migration policy in the EU. The same recommendations are fully applicable to French urban policy. Keywords: France, European Union, migration policy, intercultural dialogue, interculturalism, migrants, politique de la ville, urban policy
\end{abstract}

